\title{
Development of Quality Parameters for Yogurt with Strawberry Juice
}

\author{
Mohammad Tanzilur Rahman*, Md. Abu Zubair, Kamrunnahar Shima, Manasvi Prasad Chakma
}

Department of Food Technology and Nutritional Science, Mawlana Bhashani Science and Technology University, Santosh, Tangail, Bangladesh

Email: *mo.tanzilur.rahman@gmail.com

How to cite this paper: Rahman, M.T., Zubair, Md.A., Shima, K. and Chakma, M.P. (2020) Development of Quality Parameters for Yogurt with Strawberry Juice. Food and Nutrition Sciences, 11, 1070-1077. https://doi.org/10.4236/fns.2020.1112075

Received: October 24, 2020

Accepted: December 19, 2020

Published: December 22, 2020

Copyright $\odot 2020$ by author(s) and Scientific Research Publishing Inc. This work is licensed under the Creative Commons Attribution International License (CC BY 4.0).

http://creativecommons.org/licenses/by/4.0/

\begin{abstract}
In this research, we improve the quality parameter of prepared yogurt using different levels $(5 \%, 10 \%$, and $15 \%)$ of strawberry juice. We investigated different organoleptic, chemical and microbiological quality characteristics. We found that plain yogurt is clearly better than $15 \%$ strawberry juice yogurt while $5 \%$ strawberry juice yogurt is almost as like as the plain yogurt. Acceptance of $10 \%$ strawberry juice yogurt is between $5 \%$ and $15 \%$. We note that the organoleptic characteristics decrease with the addition of strawberry juice level. Analyzed chemical composition showed that strawberry juice incorporation increases the moisture content and acidity from $0 \%$ to $15 \%$ as strawberry juice contains higher moisture content $(90.329 \%)$ and acidity (1\%) than collected milk which contains $87.15 \%$ moisture content and $0.19 \%$ acidity. On the other hand, ash and fat content decreases as strawberry juice contains low ash $(0.311 \%)$ and fat $(1.64 \%)$ content than collected milk which contains $0.74 \%$ ash and $4.36 \%$ fat. Thus, nutritional quality decreases with the addition of strawberry juice. After performing the microbiological tests, it was recommended to consume the samples before the 5th day. We also found that various types of microbial (TPC, TCC, TFC) counts decline due to the high acidity of strawberry juice.
\end{abstract}

\section{Keywords}

Strawberry Juice, Milk, Yogurt, Organoleptic, Chemical, Microbiological

\section{Introduction}

Yogurt is a fermented milk product. It is a probiotic which helps in digestion. Among different types of fermented milk products like yogurt, fermented milk, cheese, butter, milk and ice-cream, yogurt is one of the most popular ones and 
consumed all over the world. According to the dairy council specifications, a whole cream of $100 \mathrm{gm}$ yogurt sample gives $79 \mathrm{kcal}$ energy [1]. It is noted that the food habit of people is changing and people prefer fresh, healthy and delicious foods. Though yogurt is a nutritious food, we need to improve the nutritional quality of it because nutritional related problems are prevalent all over the world and there is always seen a shortage of food because of the increasing population. For this reason, eating a small amount of food and getting a high amount of energy is the best way to solve this problem. To complete this experiment, we need to find a nutritious source to improve the nutritional quality of yogurt.

There are many experiments done on yogurt after incorporating with fruit juices. Chemical, microbiological and organoleptic tests were performed after incorporating $4 \%, 6 \%$ and $8 \%$ beetroot juice in goat milk yogurt where $4 \%$ selected as the best of them [2]. These tests were also performed after incorporating watermelon juice in yogurt samples [3]. After the addition of 2.5\%, 5.06, 7.56 and $10.0 \%$ concentrated mulberry pekmez juice, the impact on the quality and fermentation process of yogurt samples were analyzed [4]. Different quality parameters of novel fruit-yogurts were observed after the addition of different percent of white dragon fruit juice [5]. These tests were also measured for yogurts after the addition of 5\%, 10\% and 15\% mango juice [6]. Some other fruits like jackfruit [7] [8], banana [9], blueberry [10], carob [11], 1:1 ratio of apple and orange [12], etc. were also used in many studies for the development of yogurt. But these experiments discussed above were not satisfactory in many aspects. Hence, further investigation required that motivates us to conduct this study.

There are many fruits and vegetables grown in the world like mango, banana, jackfruit, etc. Those are available in nature and most of them are turned into spoilage due to lack of storage system. Development of yogurt by incorporating fruit juices is a tremendous idea to solve the storage problem, nutritional related problems and also the problem of changed food habits. The study of yogurt developed with strawberry juice and quality parameters were analyzed before [13] [14]. But, the results were not satisfactory. The popularity of strawberry is increasing day by day. Now, it has great socioeconomic importance. It is going to be the most popular fruit all over the world. Its production is increasing day by day and turns into spoilage quickly due to lack of proper storage. This is the reason why we believe that strawberry would be the perfect fruit for the development of yogurt.

In this research, an investigation was carried out among different strawberry juice yogurt samples with the addition of different levels of strawberry juice as $\mathrm{P}$ ( $0 \%$ or plain yogurt) and other samples of $5 \%, 10 \%$ and $15 \%$ strawberry juice yogurt. Organoleptic, chemical and microbiological quality assessment was done to complete this product development experiment. Development of organoleptic characteristics has a great impact on changing food habit. How the regular organoleptic characteristics of yogurt changed after incorporating strawberry juice 
was investigated. Analyzing the chemical composition was performed to see the nutritional quality improvement of prepared yogurt samples. We conduct microbiological tests including total plate count (TPC), total coliform count (TCC), and total fungal count (TFC) to find the exact shelf life of the products and to see the microbial growth after altering the acidity. We maintained room temperature throughout the course of the experiment in our laboratory.

\section{Materials and Methods}

\subsection{Materials}

For our experiments, we collected unbranded milk, strawberry fruit and sugar from the local market which is located at Tangail region of Bangladesh. Standard instruments were used for this study.

\subsection{Preparation of Strawberry Juice}

Collected strawberry (Fragaria ananassa) was washed with clean water and the skin was separated with the help of a knife aseptically. The seeds were removed from the strawberry and also the black spots were removed. Strawberry was blended and filtered with a clean cloth. These were kept in plastic containers and stored at freezing temperature $\left(-20^{\circ} \mathrm{C}\right)[13]$ until preparation of yogurt.

\subsection{Preparation of Yogurt Samples}

Whole milk was pasteurized and heated to reduce about one-third of its original volume. Sugar was added to the milk at the rate of $12 \%$ after boiling. During heating, milk was heating continuously with the help of a stirrer to avoid the formation of the cream layer. After the desired heating milk pan was taken out from the heater and allowed to cool. When the temperature was about $\left(40^{\circ} \mathrm{C}\right)$, then the milk was divided into four equal portions and a different type of yogurt was prepared from each portion. The strawberry juice, which was previously pasteurized, was incorporated into the milk at 5\%,10\% and $15 \%$ level in different cups except for the control. The juice was added before incubation with starter culture. Milk was inoculated with a desirable proportion of starter culture (2\%), which was collected from the local market. The small glass bottle was pre-washed with boiled water before use. The samples were incubated at $\left(37^{\circ} \mathrm{C}\right)$ until the total curd formation/coagulation of yogurt ( $8-12 \mathrm{~h}$ ). The yogurt samples were stored at about $4^{\circ} \mathrm{C}$ at refrigeration [15] until used.

\subsection{Organoleptic Quality Analysis Procedure}

The most common method used to measure food preferences is a questionnaire of generated foods or food categories in which a hedonic scale is used to rate the degree of likings. The hedonic scale is an organoleptic quality rating scale where the judge expresses his degree of likings. Overall tests were conducted by using 9 points Hedonic scale [16]. The general form of the organoleptic Hedonic scale was used in the following rated: 1) Dislike extremely, 2) Dislike very much, 3) 
Dislike moderately, 4) Dislike slightly, 5) Neither like nor dislike, 6) Likely slightly, 7) Like moderately, 8) Like very much, 9) Like extremely.

\subsection{Chemical Composition Analysis Procedure}

Moisture, total solids, ash content, acidity, fat and $\mathrm{pH}$ content of the selected samples were analyzed according to AOAC 1995 [17]. Water content or moisture content is the quantity of water contained in a material. The total solids content includes both the suspended solids and dissolved salts. The total solids content is also used to determine a sludge dry weight (expressed as a \%). Ash refers to any inorganic material, such as minerals, present in food. It's called ash because it's a residue that remains after heating removes water and organic material such as fat and protein. Food acids are usually organic acids, with citric, malic, lactic, tartaric, and acetic acid. A simple estimate of the total acid content of the food also called total acidity. Acidity is the amount of hydronium ion $\left(\mathrm{H}_{3} \mathrm{O}^{+}\right)$in an aqueous solution. $\mathrm{pH}$ is the scale of how we measure that concentration. A low-acid food is defined as food having a $\mathrm{pH}$ of more than 4.6, while a high-acid food is defined as a food with a $\mathrm{pH}$ value of 4.6 or lower. Fat is also known as lipid and is mainly present in food in a form called "triglycerides". Triglycerides consist of glycerol and three ("tri") fatty acids.

\subsection{Microbiological Analysis Procedure}

Total plate count (TPC), total coliform count (TCC), total fungal count (TFC) microbiological tests were conducted according to the method as described in the standard methods for the examination of dairy products [18].

\section{Results and Discussions}

\subsection{Analysis of the Chemical Composition of Experimental Raw Milk and Strawberry Juice}

In Table 1, some important nutritional constituents were analyzed separately for milk and strawberry juice to identify their chemical qualities. $87.15 \%$ of moisture content was found in milk. The solid content of milk was $12.85 \%$. Fat and ash content of the samples were found at $4.36 \%$ and $0.74 \%$ respectively. $0.19 \%$ of acidity and $\mathrm{pH} 6.7$ were measured in investigated milk which was also found by [8]. A high amount of moisture content was found in strawberry juice and the amount was $90.329 \% .9 .671 \%$ of total solid content was found in strawberry juice. The fat and ash content of the sample was $1.64 \%$ and $0.311 \%$ respectively. Acidity was high in juice and the amount was $1 \% . \mathrm{pH}$ content of the juice was 3.34. These amounts put a great effect on the final strawberry juice yogurt samples.

\subsection{Analysis of Organoleptic Tests among Different Types of Yogurt Samples}

Organoleptic tests measured on its appearance, then color, flavor and smell, 
texture, body and consistency, and overall taste acceptance. In Table 2, the overall band score of all types prepared yogurt was acceptable in quality but their specific characteristics differ slightly by the test panel board which consists of 7 members. The participants of the board were recruited through an advertisement. There were 3 females and 4 male participants aged between 30 and 50 . Note that participation in this study was voluntary. It was observed that with the addition of strawberry juice level the organoleptic characteristics were decreased. Thus it can be said that $15 \%$ strawberry juice yogurt and plain yogurt were significantly different from each other. And 5\% strawberry juice yogurt was almost as like as the plain yogurt because both samples scored between 7 i.e. like moderately and 8 , i.e., like very much. The experiments were repeated 3 times while we reported the average in this research.

Table 1. Chemical composition of experimental raw milk and strawberry juice.

\begin{tabular}{ccc}
\hline Constituent & Amount in milk & Amount in strawberry juice \\
\hline Moisture (\%) & 87.15 & 90.329 \\
Total Solid (\%) & 12.85 & 9.671 \\
Fat (\%) & 4.36 & 1.64 \\
Ash (\%) & 0.74 & 0.311 \\
Acidity (\%) & 0.19 & 1 \\
pH & 6.7 & 3.34 \\
\hline
\end{tabular}

Table 2. Organoleptic characteristics and proximate composition in different samples of plain yogurt and prepared strawberry yogurt. NOTE: Mean of 07 scores for each sensory characteristic. $P=$ Milk $+0 \%$ Strawberry Juice, $S_{1}=$ Milk $+5 \%$ Strawberry Juice, $S_{2}=$ Milk $+10 \%$ Strawberry Juice, $S_{3}=$ Milk $+15 \%$ Strawberry Juice.

\begin{tabular}{|c|c|c|c|c|c|}
\hline & Constituent & $P(0 \%)$ & $S_{1}(5 \%)$ & $S_{2}(10 \%)$ & $S_{3}(15 \%)$ \\
\hline \multirow{6}{*}{$\begin{array}{l}\text { Organoleptic } \\
\text { characteristics }\end{array}$} & Appearance & 8 & 7.14 & 6.29 & 5.14 \\
\hline & Color & 8 & 7 & 6.14 & 4.68 \\
\hline & Flavor and Smell & 7.57 & 7.29 & 6.29 & 5.14 \\
\hline & Texture & 7.71 & 7.57 & 6 & 4.57 \\
\hline & Body and Consistency & 7.57 & 7.71 & 6 & 4.71 \\
\hline & Overall Taste Acceptance & 8 & 7.43 & 6 & 4.71 \\
\hline \multirow{6}{*}{$\begin{array}{l}\text { Chemical } \\
\text { composition }\end{array}$} & Moisture (\%) & 71.79 & 71.83 & 71.85 & 71.93 \\
\hline & Total Solid (\%) & 28.21 & 28.17 & 28.15 & 28.07 \\
\hline & Fat (\%) & 4.72 & 4.35 & 4.11 & 4.07 \\
\hline & Ash (\%) & 0.78 & 0.75 & 0.72 & 0.69 \\
\hline & Acidity (\%) & 0.7 & 0.8 & 0.8 & 0.9 \\
\hline & $\mathrm{pH}$ & 4.48 & 4.00 & 3.98 & 3.97 \\
\hline
\end{tabular}




\subsection{Analysis of Chemical Composition of Different Samples of Yogurt}

Table 2 shows chemical composition of different types of prepared yogurt samples for the identification of their nutritional quality improvement. In comparing chemical analysis, it was observed that moisture content and acidity were increased in prepared yogurt with strawberry juice incorporation because strawberry juice contains higher moisture content $(90.329 \%)$ and acidity (1\%). It was observed that $\mathrm{P}$ ( $0 \%$ or plain yogurt) contains lower moisture content $(71.79 \%)$ and other samples of $5 \%, 10 \%$ and $15 \%$ contain $71.83 \%, 71.85 \%$ and $71.93 \%$ respectively. It was also observed that $\mathrm{P}(0 \%$ or plain yogurt) contains lower acidity content $(0.7 \%)$ and the other samples of $5 \%, 10 \%$ and $15 \%$ contain $0.8 \%, 0.8 \%$ and $0.9 \%$ respectively. $\mathrm{pH}$ content decreased as $\mathrm{P}(0 \%$ or plain yogurt) contains $\mathrm{pH}$ (4.48) and other samples of 5\%, $10 \%$ and $15 \%$ contain $4.00,3.98 \%$ and $3.97 \%$ respectively. On the other hand, ash and fat content were decreased with the addition of strawberry juice because strawberry juice contains low ash (0.311) and fat $(1.64 \%)$ content. It was observed that $\mathrm{P}$ ( $0 \%$ or plain yogurt) contains higher fat content $(4.72 \%)$ and the other samples of $5 \%, 10 \%$ and $15 \%$ contain $4.35 \%$, $4.11 \%$ and $4.07 \%$ respectively. It was also observed by chemical composition analysis that $\mathrm{P}$ ( $0 \%$ or plain yogurt) contains higher ash content $(0.78 \%)$ and the other samples of $5 \%, 10 \%$ and $15 \%$ contain $0.75 \%, 0.72 \%$ and $0.69 \%$ respectively. Thus, total solid content increases as $\mathrm{P}$ ( $0 \%$ or plain yogurt) contains $(28.21 \%)$ the other samples of $5 \%, 10 \%$ and $15 \%$ contain $28.17 \%, 28.15 \%$ and $28.07 \%$ respectively.

\subsection{Microbiological Quality Assessments of Different Yogurt Samples}

TPC, TCC and TFC tests were performed to compare the microbiological quality of prepared strawberry yogurt samples. After performing the microbiological tests, it was recommended to consume the samples before the 5th day because after investigating in 5 th day the number of coliform bacteria $1.2 \times 10^{5}$ was found in $15 \%$ strawberry yogurt which was not in the normal range. The number of coliforms in yogurt must be less than $1 \mathrm{CFU} \mathrm{g}^{-1}$ [19]. And fungus was formed in all other samples as plain yogurt contains $6.4 \times 10^{5}$ and $5 \%, 10 \%$ and $15 \%$ contain $5.6 \times 10^{5}, 4.7 \times 10^{5}$ and $3.5 \times 10^{5}$ respectively which are higher than normal level. The acceptable range of fungal count in yogurt is less than or equal to $10^{4}$ [20]. Although after passing the 9th-day bacterial count does not exceed the normal range i.e. the standard level for the bacterial count is $\leq 10^{7}[20]$ but coliform and fungal count exceeds the normal range in every sample. It was shown in the experiment that various types of microbial (TPC, TCC, TFC) counts declines from plain yogurt to $15 \%$ strawberry juice yogurt due to increase the percentage of strawberry juice addition which was high in acidity. A summary of microbial quality assessments for different types of prepared yogurt is given in Table 3. 
Table 3. Microbial quality assessments of different types of prepared yogurt in 0 day, after passing 5 days, and after passing 9 days. NOTE: $P=$ Milk $+0 \%$ Strawberry Juice, $S_{1}=$ Milk $+5 \%$ Strawberry Juice, $S_{2}=$ Milk $+10 \%$ Strawberry Juice, $S_{3}=$ Milk $+15 \%$ Strawberry Juice.

\begin{tabular}{cccccc}
\hline & Microbial Parameter & $P(0 \%)$ & $S_{1}(5 \%)$ & $S_{2}(10 \%)$ & $S_{3}(15 \%)$ \\
\hline \multirow{3}{*}{0 day } & TPC count $(\mathrm{cfu} / \mathrm{ml})$ & $2.0 \times 10^{5}$ & $1.6 \times 10^{5}$ & $1.2 \times 10^{5}$ & $1.1 \times 10^{5}$ \\
& TCC count $(\mathrm{cfu} / \mathrm{ml})$ & Nil & Nil & Nil & Nil \\
& TFC count $(\mathrm{cfu} / \mathrm{ml})$ & Nil & Nil & Nil & Nil \\
\hline \multirow{2}{*}{$\begin{array}{c}\text { after } \\
\text { passing } 5 \text { days }\end{array}$} & TPC count $(\mathrm{cfu} / \mathrm{ml})$ & $3.5 \times 10^{5}$ & $2.1 \times 10^{5}$ & $1.7 \times 10^{5}$ & $1.4 \times 10^{5}$ \\
& TCC count $(\mathrm{cfu} / \mathrm{ml})$ & Nil & Nil & Nil & $1.2 \times 10^{5}$ \\
& TFC count $(\mathrm{cfu} / \mathrm{ml})$ & $6.4 \times 10^{5}$ & $5.6 \times 10^{5}$ & $4.7 \times 10^{5}$ & $3.5 \times 10^{5}$ \\
\hline \multirow{2}{*}{ after } & TPC count $(\mathrm{cfu} / \mathrm{ml})$ & $4.8 \times 10^{7}$ & $4.7 \times 10^{7}$ & $3.8 \times 10^{7}$ & $3.3 \times 10^{7}$ \\
passing 9 days & TCC count $(\mathrm{cfu} / \mathrm{ml})$ & $1.9 \times 10^{7}$ & $1.7 \times 10^{7}$ & $1.3 \times 10^{7}$ & $1.2 \times 10^{7}$ \\
& TFC count $(\mathrm{cfu} / \mathrm{ml})$ & $6.6 \times 10^{7}$ & $6.1 \times 10^{7}$ & $4.9 \times 10^{7}$ & $4.0 \times 10^{7}$ \\
\hline
\end{tabular}

\section{Conclusion}

This study was investigated on the basis of organoleptic, chemical and microbiological analysis of $0 \%$ (plain) and 5\%, 10\%, 15\% level of strawberry juice yogurt samples. With the increasing percentage of strawberry juice level, the organoleptic quality of yogurt samples decreasing and 5\% shows a better acceptance level. In chemical analysis, nutritional quality decreases with the addition of strawberry juice. After microbiological tests like TVC, TCC and TFC, it was recommended to consume the samples before the 5th day. However, further work is needed for the development of strawberry juice yogurt. Future research may consider the effect of disinfection bias of experiment apparatus in the results. Future research also may investigate by considering other varieties of strawberry fruit and branded milk.

\section{Conflicts of Interest}

The authors declare no conflicts of interest regarding the publication of this paper.

\section{References}

[1] The Dairy Council (2013) The Nutritional Composition of Dairy Products. The Dairy Council, London.

[2] Damunupola, D.A.P.R., Weerathilake, W.A.D.V. and Sumanasekara, G.S. (2014) Evaluation of Quality Characteristics of Goat Milk Yogurt Incorporated with Beetroot Juice. International Journal of Scientific and Research Publications, 4, 1-5.

[3] Warakaulle, S.T.S.K., Weerathilake, W.A.D.V. and Abeynayake, N.R. (2014) Production and Evaluation of Set Type Yoghurt Incorporated with Water Melon ( $C i$ trallus lanatus). International Journal of Scientific and Research Publications, 4, 1-4.

[4] Celik, S. and Bakirci, I. (2003) Some Properties of Yoghurt Produced by Adding Mulberry Pekmez (Concentrated Juice). International Journal of Dairy Technology, 56, 26-29. https://doi.org/10.1046/j.1471-0307.2003.00070.x 
[5] Jayasinghe, O., Fernando, S., Jayamanne, V. and Hettiarachchi, D. (2015) Production of a Novel Fruit-Yoghurt Using Dragon Fruit (Hylocereus undatus L.). European Scientific Journal (ES), 11, 208-215.

[6] Kabir, M.A., Rashid, M.H., Hassan, M.N., Afroz, M.F. and Miraz, F.H. (2014) Manufacture of Dahi from Skim Milk Adding Mango Juice. Bangladesh Journal of Animal Science, 43, 128-131. https://doi.org/10.3329/bjas.v43i2.20713

[7] Sarmini, N., Sinniah, J. and Silva, K.F.S.T. (2014) Development of a Ripened Jack (Artocarpus heterophyllus Lain) Fruit and Soy (Glycine max) Milk Incorporated Set Yoghurt. International Journal of Dairy Science, 9, 15-23. https://doi.org/10.3923/ijds.2014.15.23

[8] Dey, K.C., Begum, R., Rahman, M.R.T., Sultana, A., Akter, S. and Janny, R.J. (2014) Development of Fruit Juice Yogurt by Utilization of Jackfruit Juice: A Preliminary Study on Sensory Evaluation, Chemical Composition and Microbial Analysis. International Journal of Engineering Research, 3, 1074-1079.

[9] Çakmakçi, S., Cetin, B., Turgut, T., Gürses, M. and Erdoğan, A. (2012) Probiotic Properties, Sensory Qualities, and Storage Stability of Probiotic Banana Yogurts. Turkish Journal of Veterinary and Animal Sciences, 36, 231-237.

[10] Cinbas, A. and Yazici, F. (2008) Effect of the Addition of Blueberries on Selected Physicochemical and Sensory Properties of Yogurts. Food Technology and Biotechnology, 46, 434-441.

[11] Atasoy, A.F. (2009) The Effects of Carob Juice Concentrates on the Properties of Yoghurt. International Journal of Dairy Technology, 62, 228-233. https://doi.org/10.1111/j.1471-0307.2009.00465.x

[12] Shree, T.C., Venkatesh, M.M., Praveen, A.R. and Teja, V. (2017) Effect of Whey Protein Concentrate and Fruit Juice on Sensory Quality of Enriched Misti Dahi. Asian Journal of Dairy and Food Research, 36, 21-25. https://doi.org/10.18805/ajdfr.v36i01.7455

[13] Hossain, M.N., Fakruddin, M. and Islam, M.N. (2012) Development of Fruit Dahi (Yoghurt) Fortified with Strawberry, Orange and Grape Juice. American Journal of Food Technology, 7, 562-570. https://doi.org/10.3923/ajft.2012.562.570

[14] Oliveira, A., Alexandre, E.M., Coelho, M., Lopes, C., Almeida, D.P. and Pintado, M. (2015) Incorporation of Strawberries Preparation in Yoghurt: Impact on Phytochemicals and Milk Proteins. Food Chemistry, 171, 370-378. https://doi.org/10.1016/j.foodchem.2014.08.107

[15] Mymensingh, B. (2007) A Comparative Study on the Quality of Dahi (Yoghurt) Prepared from Cow, Goat and Buffalo Milk. International Journal of Dairy Science, 2, 260-267. https://doi.org/10.3923/ijds.2007.260.267

[16] Peryam, D.R. and Pilgrim, F.J. (1957) Hedonic Scale Method of Measuring Food Preferences. Food Technology, 11, 9-14.

[17] AOAC, Horwitz, W. (Ed.) (1995) Official Methods of Analysis. 14th Edition, The Association of Official Analytical Chemists, Washington DC.

[18] Cato, T.E., Mickle, F.L., Tiedeman, W.D., Johns, C.K., Slocum, G.G., Black, L.A. and Robertson, A.H. (1952) Standard Methods for the Examination of Diary Products. Proposed Changes for the Tenth Edition. American Journal of Public Health and the Nations Health, 42, 1131-1134. https://doi.org/10.2105/AJPH.42.9.1131

[19] SSI (1989) Specification for Fermented Milk Products-Part 2-Yoghurt. Amendment No. 01 to SLS 824, Sri Lanka Standard Institute, Colombo, 2-9.

[20] Chowdhury, N.A., Kamruzzaman, P. and Zaman, W. (2011) Study on the Quality Assessment of Curd (Dahi), Locally Available in Bangladeshi Market. World Journal of Dairy and Food Sciences, 6, 15-20. 